composition for use in climates where it is undesirable that metal should come in contact with the skin. They are more easily broken than if made of metal, but, on the other hand, they can be more readily adjusted to the soldier's face by softening the composition in warm water and by then moulding them with the finger to the desired shape. The straight sides of the frame are pierced by a small hole, so that if they become loose they can be readily fastened round the soldier's head. The necessary prescriptions and measurements for glasses are furnished by the different medical officers and transmitted to the Army Spectacle Depôt, which in due course supplies the spectacles. A word concerning the Depôt itself, which is at Clifford's Inn Hall, Fleet Street, E.C.4, where a staff of about 100 girls, superintended by Mr. J. H. Sutcliffe and assisted by three or four R.A.M.C. optical mechanics, have been trained in the various processes of turning out spectacles for the 200 ophthalmic centres established by the Army Medical Department at home and on the different fronts. We hope to publish before long a full account of the work from the pen of the Superintendent of the Army Spectacle Depôt.

\title{
Optometry in Ontario
}

Readers may recall the fact that we animadverted in these columns (August, 1918) on the proposals made by Mr. Justice Hodgins with regard to optometry in Ontario, Canada. We are now glad to observe that the Ontario Medical Association has expressed its views upon the subject (Canada Lancet, December, 1918). The Association protests against Mr. Justice Hodgins's proposal to create any sort of quasi-profession with just enough medical knowledge to prove dangerous to the public. There can be no objection to some provision in the legislation of the Province whereby all those outside the medical profession who do refraction work and prescribe glasses must first obtain a certificate of competency for such work from an accredited board. But beyond this the law should not go in the recognition of a separate body. Neither can the Association concur in Mr. Justice Hodgins's recommendation that the universities should provide additional courses of instruction. It thinks that a better plan would be to lay upon the universities the responsibility of furnishing to medical students a more extensive course on refraction than that at present given. This would tend to supersede the need for the optometrist. As to the Commissioner's three recommendations that the optometrist should be given (1) adequate knowledge of medicine to detect disease in the body disclosed or indicated by the eye, (2) acquaintance with the physiology and the pathology of the eye 
adequate to recognize local disease, and (3) a thorough knowledge of practical optics and refraction, the Association holds that the clause last named is all that is required for opticians. The other clauses could be carried out only as part of a medical course. The medical colleges cannot arrange special courses for such purposes, nor can they fit optometrical students into the regular courses now in existence. To institute a special college for the purpose has all the objections of creating a quasi-profession and of multiplying the difficulties now existing rather than of simplifying them. While the Association approves of a good training for opticians, such as may be obtained from technical schools and from experienced opticians, it thinks that the logical solution of the optometrist difficulty would be met by urging a more thorough course of refraction in the medical colleges. With this view we are in cordial accord, and would merely add that, in our opinion, ophthalmology should form an integral part of the final examination for medical qualification.

\section{ABSTRACTS}

\section{I.-ANISOCORIA}

Tarun, William (Baltimore). - Pupillary studies, with special reference to anisocoria. Trans. Amer. Ophthal. Soc., Vol. XV (1917), p. 30I.

Tarun has investigated the frequency and diagnostic value of inequality of the pupils, and to this end has examined records of 3,610 private patients suftering from non-inflammatory affections of the eyes. Examinations were made in a dark room with a constant source of light. The reaction of the pupil was determined with a concave mirror, used at a distance of rather more than its focal distance. Anisocoria was looked for under the same conditions with a plane mirror, at a distance of one metre from the patient. In Tarun's opinion, the daylight test should be discarded. The examination of the pupils should be made under quiet conditions, in order to exclude the psychic reflex. Two minutes should be allowed for dark adaptation. The author feels sure that on occasion Haab's cortical pupillary reflex has been mistaken for an Argyll Robertson pupil. Anisocoria was found in 19.39 per cent. of the cases examined. Normal eyes averaged 18.54 per cent., which gradually rose in diseased eyes and lesions of the nervous system until 70 per cent. was reached in the instances of Argyll Robertson pupil. Tarun is rather sceptical in believing that there is such a condition as physiological anisocoria, although Bach and 